University for Business and Technology in Kosovo

UBT Knowledge Center

Nov 2nd, 3:00 PM - 3:15 PM

\title{
Tuned Mass Damper: An Intelligent Device As A Protection System Instructural Engineering
}

\author{
Feti Selmani \\ PAN Engineering, panengineering@gmail.com \\ Musa Stavileci \\ PAN Engineering
}

Follow this and additional works at: https://knowledgecenter.ubt-uni.net/conference

Part of the Architecture Commons

\section{Recommended Citation}

Selmani, Feti and Stavileci, Musa, "Tuned Mass Damper: An Intelligent Device As A Protection System Instructural Engineering" (2013). UBT International Conference. 22.

https://knowledgecenter.ubt-uni.net/conference/2013/all-events/22

This Event is brought to you for free and open access by the Publication and Journals at UBT Knowledge Center. It has been accepted for inclusion in UBT International Conference by an authorized administrator of UBT Knowledge Center. For more information, please contact knowledge.center@ubt-uni.net. 


\title{
Tuned Mass Damper: An Intelligent Device As A Protection System Instructural Engineering
}

\author{
Feti Selmani ${ }^{1}$, Musa Stavileci ${ }^{1}$ \\ 1 PAN Engineering Prishtina, Kosovo \\ panengineering@gmail.com
}

\begin{abstract}
Nowadays, destructive environmental forces such as earthquakes, tsunamis and winds accompanied with landslides, have mobilized the minds of the civil engineering communities around the world for finding new and better means for the protection of structures. As it is well known already, the conventional design approach, requires, that the structures passively resist environmental disturbances through a combination of strength, deformability and energy dis sipation. Our experience shows that this is neither sufficient nor satisfactory. The basic role of passive energy dissipation devices when incorporated into a structure is to absorb or consume a portion of the input energy, thereby reducing energy dissipation demand on the primary structural members and minimizing possible structural damage. This paper represents an effort to strengthen the structural engineer's interest on the problem of our modern times: passive energy dissipation. In this paper we have approached one of them: Tuned Mass Damper (TMD).
\end{abstract}

Keywords: Absorption, Passive energy dissipation, Tuned Mass Damper, Optimal damping, Control

\section{Introduction}

During the design of civilengineering structures, the actions taken into account are usually those, which are acting as a consequence of gravity. They represent actions that a structure must endure during his exploitation /Design Working Life, acc. to ENV 1991-1/. Here are accounted for, not only permanent actions such as the self weight of the structure itself, but also those actions that takes place as a result of structure's exploitation. The idealization resulting by adopting of static model of actions, having into consideration their nature, seems to be acceptable /slow variation of actions/. Nowadays, material resources are frequently limited. For this reason, during the process of structuraldesign, rais es the need for structural optimization. Having said that, static model is no more valid. Altogether and added the stochastic nature of ambient phenomena such as strong winds accompanied by earthquakes and landslides, arises the need for development of new ideas and concepts of structural protection systems. Various concepts and innovative technologies are under experimental and practical imple mentation. This paper represents a temptation to raise the attention of our community relatively to the problemand the role of passive energy dissipation devices in first, absorbing and after dissipating the input energy of an earthquake or environmental hazard. One of the most evident advantages of seismic isolation is that offers to the structure the possibility to be flexible, meanwhile to behave as ess entially rigid. Every external perturbation can be imagined as an energetic "injection" into the civil engineering structure, whereas the design consists on the "management" of this input energy inside the structure. The primary role of passive energy dissipation devices, when incorporated in a structure, consists in absorbing the input energy, respectively in reducing the absorption demand of the primary structural elements, resulting in an increase in its /structure's/ survivability.

These last years, a feasible technology is used in many parts of the world (Japan, USA), whereas constant efforts are under way for improvement and further development of the concept. A number of those structural protective systems [11] has already passed the test (e.g., Taipei 101) successfully. Having into consideration the applied approaches for this energy input management, the pas sive energy dissipation devices are classified as it follows [6]:

- Metallic Dampers

- Friction Dampers 
- Viscoelastic Dampers

- Viscous Dampers

- Tuned Mass Damper/s

- Tuned Liquid Dampers

- Liquid Wall Dampers etc...

Let us consider the lateral motion of a single-degree-of-freedom (SDOF) mathematical model, shown in Figure 1, consisting of a mass $m$, supported by a shear frame with total linear elastic stiffness $k$, a damper with linear viscosity $c$ and the generic passive damper element (device) $\Gamma$.

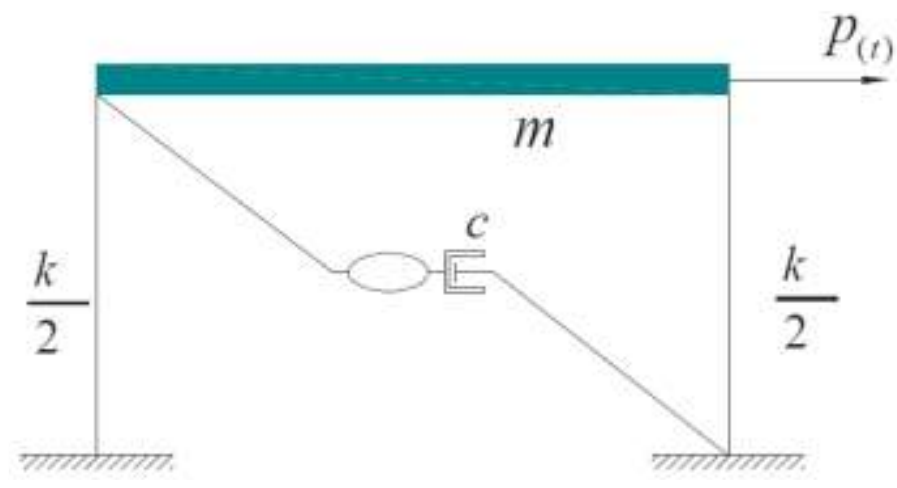

Fig. 1. Simplified SDOF shear frame structure under the influence of a harmonic action $p(t)$

The dynamic response of the structure will be influenced, of course, from this supplementary devices (non-viscous in their nature) which will "support" the primary structure with a supplementary strength ("muscle"), i.e. it will improve the resistance capacity of the structure. Symbol represents a generic integro-differential operator [Soong] such that its corresponding force is . In this way, the differential equation governing the response of the system given in Fig. 1 The plot giving the relation forcedisplacement, for the damper/device/ with mass $m d$ and generic damping ratio [6] is shown in Fig.2, where it can be seen that the damper (device) is modeled in form of an elastic-perfectly plastic (elastoplastic) element, having as initial stiffness and yield strength .

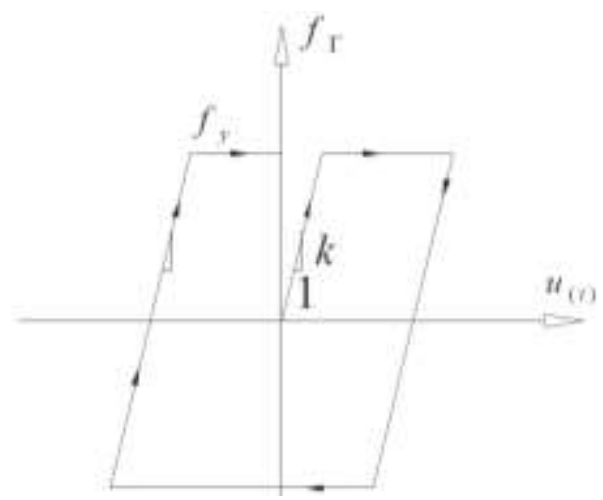

Fig. 2. Simplified elastic-perfectly plastic (elastoplastic) force-deformation relation

\subsection{Tuned Mass Damper}

A very elegant way to protect structures, especially when wind induced forces are into question is, the tuned mass damper (TMD). TMD consists of mass with properly tuned spring and damper attached to the primary (main) structure, providing with a frequency-dependent hysteresis loop that increases considerably the damping of the primary structural system. The main objective, is, that the natural frequency of the TMD has to be tuned with a chosen natural frequency of the primary structure (mainly 
the fundamental one for MDOF, the first for SDOF). When this primary structure's frequency is exited, the TMD will resonate out of phase with the structural motion, permitting thus energy dissipation by the TMD inertia force acting on the structure. The basic principle of TMD has been laid by Frahm 1909, in reducing the rolling motion of ships as well as ship hullvibrations, whereas theoreticalbas is has been given by the Dutch engineer J. Den Hartog in his notorious book Mechanical Vibrations in 1940.

Since then, the principle has been used in mechanical engineering and only in the late eighties found some application in structural and civil engineering. In order to expose the problem in a simple and clear manner, let us consider the mathematical model given as indicated in fig.3, below. The primary structure is excited by the harmonic force, whereas the ground moves according to the periodic law .

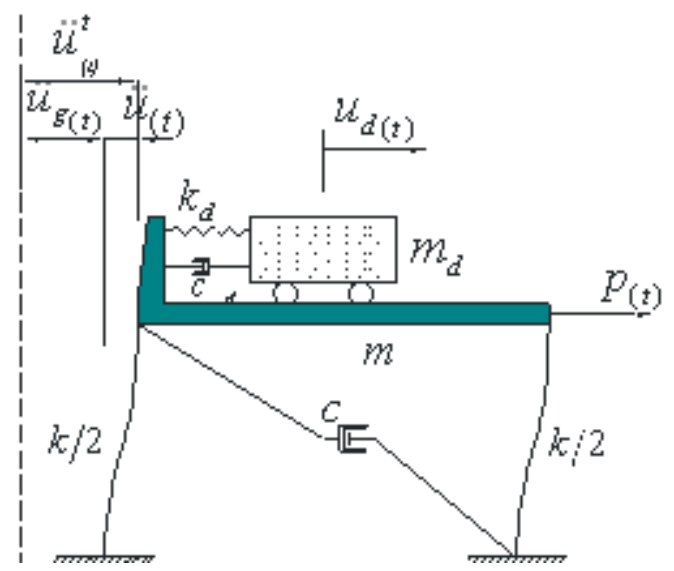

Fig. 3. Simplified mathematical model of a two degrees-of-freedom structure under the influence of a harmonic action $p(t)$

Sometimes, in order to better estimate the beneficiary contribution of TMD in the absorption and subsequently the dissipation of the input energy, the primary damping $c$ is taken from the structure (Fig. 3).

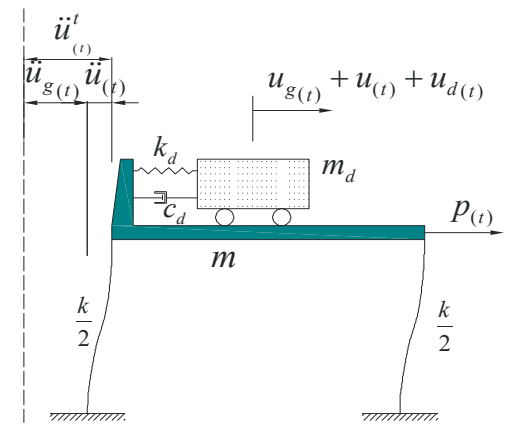

Fig. 4. Simplified mathematical model of a two degrees -of-freedom structure for the undamped primary structure $c=0$, under the influence of a harmonic action $p(t)$

The equations of equilibrium after the application of the d'Alembert's principle (fig.4c) are:

$$
\begin{aligned}
& m \ddot{u}_{(t)}+k u_{(t)}-k_{d} u_{d(t)}-c_{d} \dot{u}_{d(t)}=p_{(t)}-m \ddot{u}_{g(t)} . \\
& m_{d} \ddot{u}_{d(t)}+c_{d} \dot{u}_{d(t)}+k_{d} u_{d(t)}+m_{d} \ddot{u}_{d(t)}=-m_{d} \ddot{u}_{g(t)} .
\end{aligned}
$$


The differential equation (2) governs the motions of the primary structure's mass, whilst equation (3) governs the motions of the TMD. After addition of the equation (2) and equation (3), we obtain the differential equation, governing the motions of the combined structure (3.1) as follows:

$$
\left(m+m_{d}\right) \cdot \ddot{u}_{(t)}+k u_{(t)}=-\left(m+m_{d}\right) \cdot \ddot{u}_{g(t)}-m \ddot{u}_{d(t)}+p_{(t)} .
$$

where

$$
\begin{array}{ll}
m & \text { primary structure's mass } \\
m_{d} \quad \text { tuned mass damper's mass } \\
k \quad \text { primary structure's stiffness } \\
k_{d} \quad \text { tuned mass damper's stiffness }
\end{array}
$$

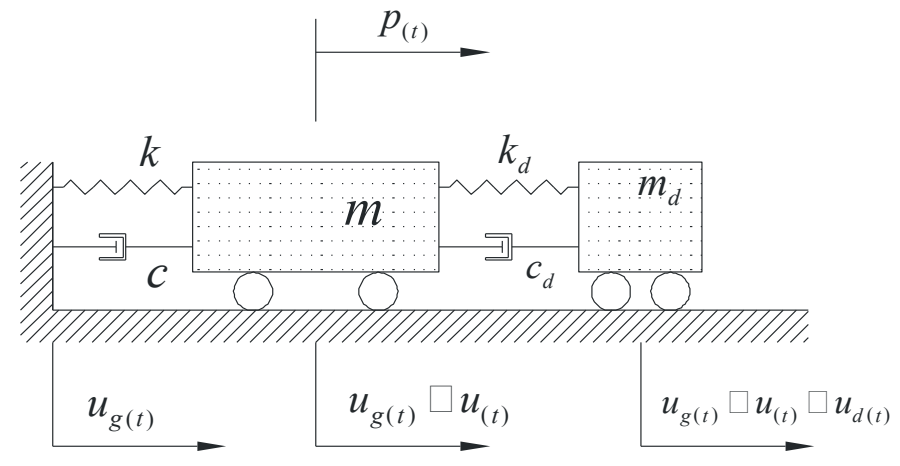

Fig. 4a. Simplified mathematical model of a two degrees-of-freedom structure under the influence of a harmonic action $p(t)$, mass-spring-damper model

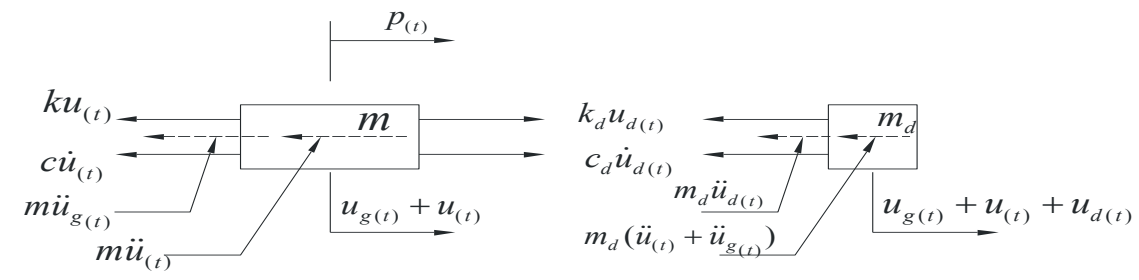

Fig. 4b. D'Alembert principle applied to the equilibrium of the two degrees-of-freedom mass-springdamper model

The equations of equilibrium after the application of the d'Alembert's principle (Fig.4b) once again are:

$$
\begin{aligned}
& m \ddot{u}_{(t)}+k u_{(t)}-k_{d} u_{d(t)}-c_{d} \dot{u}_{d(t)}=p_{(t)}-m \ddot{u}_{g(t)} . \\
& m_{d} \ddot{u}_{d(t)}+c_{d} \dot{u}_{d(t)}+k_{d} u_{d(t)}+m_{d} \ddot{u}_{d(t)}=-m_{d} \ddot{u}_{g(t)} .
\end{aligned}
$$


The differential equation (2) governs the motions of the primary structure's mass, whereas equation (3) governs the motions of the TMD. After addition of the equation (2) with equation (3) we obtain the differential equation, governing the motions of the combined structure (3.1) as follows:

$$
\left(m+m_{d}\right) \cdot \ddot{u}_{(t)}+k u_{(t)}=-\left(m+m_{d}\right) \cdot \ddot{u}_{g(t)}-m \ddot{u}_{d(t)}+p_{(t)} .
$$

where

$$
\begin{array}{ll}
m \quad \text { primary structure's mass } \\
m_{d} \quad \text { tuned mass damper's mass } \\
k \quad \text { primary structure's stiffness } \\
k_{d} \quad \text { tuned mass damper's stiffness } \\
\ddot{u}_{(t)} \quad \text { relative acceleration of the primary structure's mass } \\
\ddot{u}_{g_{(t)}} \quad \text { ground acceleration } \\
c_{d} \quad \text { tuned mass damper's damping coefficient } \\
\dot{u}_{d(t)} \quad \text { velocity imposed to the tuned mass damper } \\
u_{d(t)} \quad \text { displacement of the TMD's mass at a given time instant } t \\
p_{(t)} \quad \text { external excitation (e.g. wind) }
\end{array}
$$

To solve differential equations (2) and (3), let analyze the case when the ground moves according to the law (4) whereas the external force varies according to the equation (5)

$$
\begin{gathered}
\ddot{u}_{g(t)}=\ddot{u}_{g 0} e^{i \Omega t} . \\
p_{(t)}=p_{0} e^{i \Omega t} .
\end{gathered}
$$

Dynamic response is supposed as given per equations (6) and (7)

$$
\begin{aligned}
& u_{(t)}=u_{0} e^{i \Omega t} . \\
& u_{d(t)}=u_{d 0} e^{i \Omega t}
\end{aligned}
$$

After introducing the expressions (4), (5), (6) and (7) into the expressions (2) and (3) we obtain:

$$
\begin{aligned}
& \left(m_{d} \Omega^{2}+i c_{d} \Omega+k_{d}\right) u_{d 0}-m_{d} \Omega^{2} u_{0}=-m_{d} \ddot{u}_{g 0} . \\
& -\left(i c_{d} \Omega+k_{d}\right) u_{d 0}+\left(-m \Omega^{2}+k\right) u_{0}=-m \ddot{u}_{g 0}+p_{0} .
\end{aligned}
$$

From the expressions (8) and (9) after transformation of complex solutions into polar ones the solutions for and, became: 


$$
\begin{array}{r}
u_{0}=\left(p_{0} / k\right) A_{1} e^{i \delta_{1}}-\left(m \ddot{u}_{g 0} / k\right) A_{2} e^{i \delta_{2}} . \\
u_{d}=\left(p_{0} / k\right) A_{3} e^{-i \delta_{3}}-\left(m \ddot{u}_{g 0} / k\right) A_{4} e^{-i \delta_{3}} .
\end{array}
$$

Factors $(\mathrm{i}=1,4)$, in the expressions (10) and (11), define the amplification of pseudo-static responses, whilst the factors represent phase angles of external forces (ground motion or wind action) as well as dynamic responses of the structure. These amplification factors are given as it follows:

$$
\begin{aligned}
A_{1} & =\frac{\sqrt{\left(f^{2}-\rho^{2}\right)+\left(2 \zeta_{d} \rho f\right)^{2}}}{\left|D_{2}\right|} . \\
A_{2} & =\frac{\sqrt{\left((1+\mu) f^{2}-\rho^{2}\right)^{2}+\left(2 \zeta_{d} \rho f(1+\mu)\right)^{2}}}{\left|D_{2}\right|} . \\
A_{3} & =\frac{\rho^{2}}{\left|D_{2}\right|} . \\
A_{4} & =\frac{1}{\left|D_{2}\right|} . \\
\left|D_{2}\right|=\sqrt{\left(\left(1-\rho^{2}\right)\left(f^{2}-\rho^{2}\right)-\mu \rho^{2} f^{2}\right)^{2}+\left(2 \zeta_{d} \rho f\left(1-\rho^{2}(1+\mu)\right)\right)^{2}} & \\
\delta_{1} & =\alpha_{1}-\delta_{3} . \\
\delta_{2} & =\alpha_{2}-\delta_{3} . \\
\tan \alpha_{2} & =\frac{2 \zeta_{d} \rho f(1+\mu)}{(1+\mu) f^{2}-\rho^{2}} . \\
\tan \delta_{3} & =\frac{2 \zeta_{d} \rho f\left(1-\rho^{2}(1+\mu)\right)}{\left(1-\rho^{2}\right)\left(f^{2}-\rho^{2}\right)-\mu \rho^{2} f^{2}} . \\
& \frac{2 \zeta_{d} \rho f}{\left(f^{2}-\rho^{2}\right)} .
\end{aligned}
$$

where: $\mu=\frac{m_{d}}{m} . \quad$ mass ratio

$$
\begin{aligned}
\omega^{2}=\frac{k}{m} . & \\
c & =2 \zeta \omega m .
\end{aligned}
$$




$$
\begin{gathered}
\omega_{d}{ }^{2}=\frac{k_{d}}{m_{d}} \\
c_{d}=2 \zeta_{d} \omega_{d} m_{d} \\
f=\frac{\omega_{d}}{\omega} \\
\rho=\frac{\Omega}{\omega} \\
\begin{array}{cl}
\omega_{d} & \text { circular frequency of the TMD } \\
\omega & \quad \text { circular frequency of the primary structure } \\
\Omega & \text { circular frequency of exciting force or ground motion }
\end{array}
\end{gathered}
$$

Ratio between the mass of TMD and the mass of primary structure, for the majority of practical cases in structural engineering is $\mu \leq 0,05$. From this it results that amplification factors for both external forces $A_{1}$ and ground motions $A_{2}$ are approximately equal $\left(A_{1} \approx A_{2}\right.$.) This holds also for phase angles $\left(\delta_{1} \approx \delta_{2}\right)$.

The main reason for incorporating the TMD is to bring the amplitude $A_{1}$ at its lowest possible value whereas holding the ratio $\rho$ as much as possible near 1 (the case of classic resonance). The minimum of this value can be achieved by optimizing the $f$ ratio in such a way that it takes the value below:

$$
f_{\text {opt }}=\frac{1}{1+\mu} .
$$

For $f=f_{\text {opt }}$, the amplitude of forced vibration $u_{0}$ is:

$$
u_{0}=\frac{p_{0}}{k} \sqrt{1+\frac{2}{\mu}} .
$$




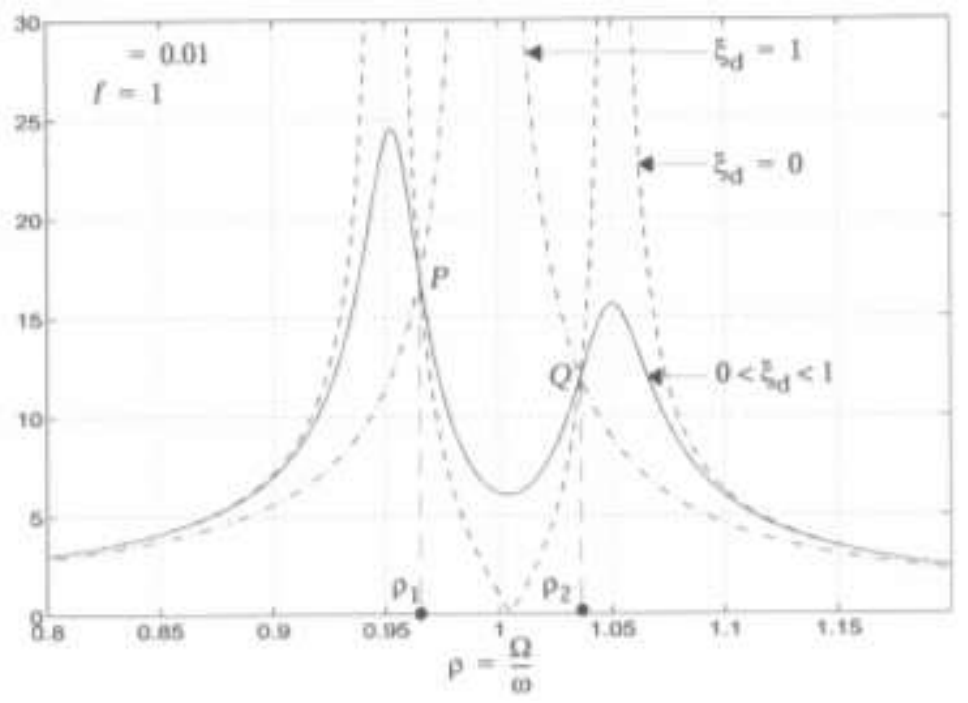

Fig. 5 Plot showing the displacement amplitudes of the primary structure for the case of mass ratio $\mu=0.01$ and the frequency ratio $f=1$. One can clearly see the position of fixed points $P$ and $Q$ are independent of damping ratio $\xi d$

Fig 5 [Den Hartog] shows the variation of the amplification factor relatively to specific values of ratios and and different values of the damping ratio. In the case when , on both sides of ratio, appears two peaks (infinite values) of coefficient . As becomes larger, these two peaks are approaching each other, and finally take the same values. This kind of behaviour let us understand that there must exist a certain value of , for which the configuration of the TMD allows the absorption and afterward the optimal dissipation of the input energy.

One another characteristic that can be observed from the Fig. 5 is that all curves passe through two points marked as $\mathrm{P}$ and $\mathrm{Q}$ (no matter what values the damping ratio takes). From this results the important fact that the position of these two points depends on coefficients and only.

As a result, the expression (13) can be transformed in the following form:

$$
A_{2}=\frac{\sqrt{a_{1}^{2}+\zeta_{d}^{2} a_{2}^{2}}}{\sqrt{a_{3}^{2}+\zeta_{d}^{2} a_{4}^{2}}}=\frac{a_{2}}{a_{4}} \sqrt{\frac{a_{1}^{2} / a_{2}^{2}+\zeta_{d}^{2}}{a_{3}^{2} / a_{4}^{2}+\zeta_{d}^{2}}} .
$$

where:

$$
\begin{gathered}
\left.a_{1}=(1+\mu) f^{2}-\rho^{2}\right) . \\
a_{2}=2 \rho f(1+\mu) . \\
a_{3}=(1-\mu)\left(f^{2}-\rho^{2}\right)-\mu \rho^{2} f^{2} . \\
a_{4}=2 \rho f\left(1-\rho^{2}(1+\mu)\right) .
\end{gathered}
$$

In this way, for an amplification factor which doesn't depend on , the following condition has to be fulfilled [Den Hartog]: 


$$
\left|\frac{a_{1}}{a_{2}}\right|=\left|\frac{a_{3}}{a_{4}}\right| .
$$

The corresponding values of , for points $\mathrm{P}$ and $\mathrm{Q}$ are:

$$
A_{2 \neg P, Q}=\left|\frac{a_{2}}{a_{4}}\right| \text {. }
$$

After introducing the corresponding values for $a_{i}$ (from 19.1 until 19.4) in the expression (20), one can obtain the quadratic equation for $\rho^{2}$ as it follows:

$$
\rho^{4}-\left[(1+\mu) f^{2}+\frac{1+0.5 \mu}{1+\mu}\right] \rho^{2}+f^{2}=0 .
$$

Expression (20.1) can be developed further:

$$
A_{2 \neg P, Q}=\left|\frac{1+\mu}{1-\rho_{1,2}{ }^{2}(1+\mu)}\right| .
$$

For an optimal behavior of the primary structure, it is needed that the amplification factor $A_{2}$ gain minimum values in the neighborhood of $\rho=1$. In order to obtain equal values of $A_{2}$ in the points $\mathrm{P}$ and $\mathrm{Q}$ one needs to fulfill the following condition:

$$
\left|1-\rho_{1}^{2}(1+\mu)\right|=\left|1-\rho_{2}^{2}(1+\mu)\right| .
$$

By replacing the corresponding values for $\rho_{1}$ and $\rho_{2}$, obtained from the equation (21) we obtain the optimal value of the coefficient $f_{\text {opt }}$ [Hartog]

$$
f_{\text {opt }}=\frac{\omega_{d, o p t}}{\omega}=\frac{\sqrt{1-0.5 \mu}}{1+\mu} .
$$

The corresponding values are:

$$
\begin{gathered}
\rho_{1,2},_{o p t}=\sqrt{\frac{1 \pm \sqrt{0.5 \mu}}{1+\mu}} \\
A_{2,{ }_{\text {opt }}}=\frac{1+\mu}{\sqrt{0.5 \mu}} .
\end{gathered}
$$

All this can be seen clearly in the Figure 6 below 


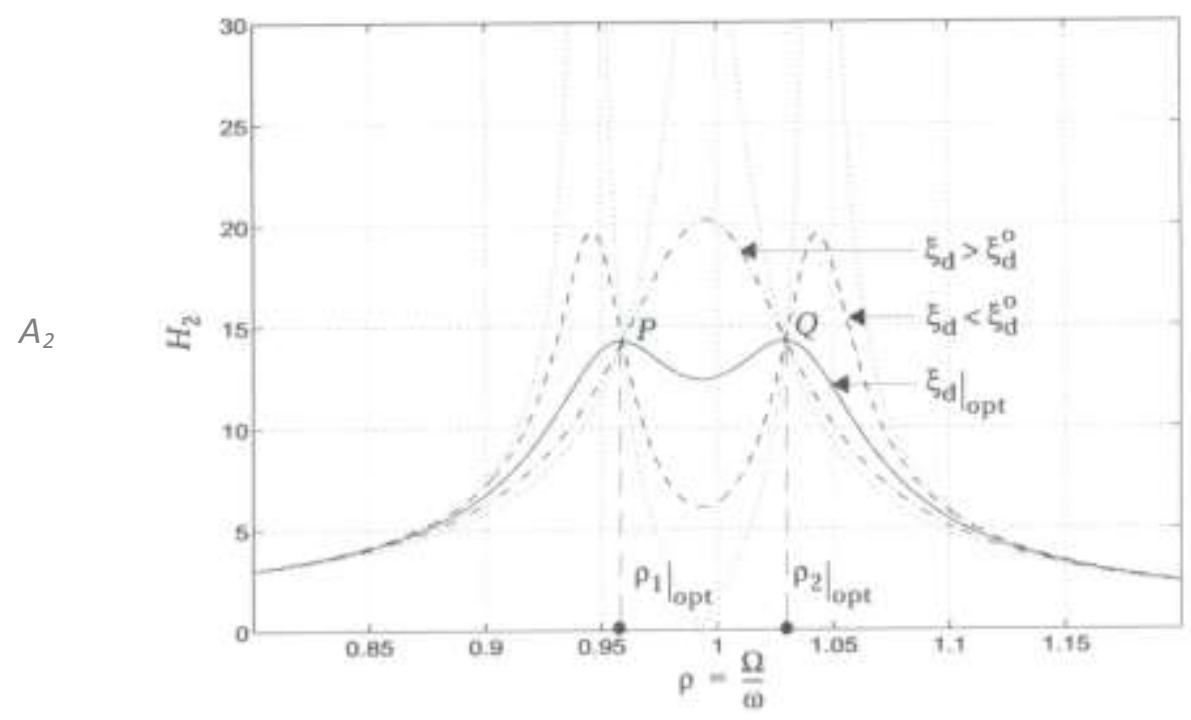

Fig. 6. Plot showing the displacement amplitudes of the primary structure for the case of the optimal damping ratio $\xi_{d}$, opt

Finally, the optimal value of the damping coefficient for the TMD is given by the expression (24) [Soong]:

$$
\zeta_{d, o p t}=\sqrt{\frac{\mu(3-0.5 \sqrt{0.5 \mu})}{8(1+\mu)(1-0.5 \mu)}} .
$$

\subsubsection{Example}

In order to better appreciate the beneficiary contribution of a TMD when mounted on the top of a structure, we will show it through two simple examples, as shown below.

- A shear frame such as the one shown in the Figure 4 above with a mass lumped at the story level $m=300 \mathrm{~kg}$ and a story stiffness $k=2 \cdot 106 \mathrm{~N} / \mathrm{m}^{\prime}$ is subject to the action of a harmonic force $p t=p 0 \cdot \sin \Omega t$, with an amplitude $p 0=3000 \mathrm{~N}$ and with a circular frequency of $\Omega=$ $110 \mathrm{rad} / \mathrm{sec}$. The task is:

First Case - TMD "control" (undamped shear frame, undamped TMD): Design a TMD in such a way that the story displacement of the primary structure vanishes completely (this is only theoretically possible) whilst the steady-state displacement amplitude of the TMD is less than $0.02 \mathrm{~m}$.

The steady-state amplitude of the tuned mass damper needs satisfy the following condition

$$
u d=p 0 k d<0.02 \mathrm{~m} \text { or, } k d>p 00.02=30000.02=150000 \mathrm{~N} / \mathrm{m}
$$

This implies that the mass ratio $\mu=m d m$, and $m d m=1 f 2 \cdot k d k$, from where results

$$
f=\omega d \omega=\Omega \omega=110 k m=1102000000300=1.347, \text { therefore }
$$


$m d m=1 f 2 \cdot k d k=11.3472 \cdot 1500002000000=0.0413, \quad$ Chosen $\quad \mu=$ $m d m=0.06$

Using a short script within Matlab, will yield the steady-state amplitudes of the primary shear frame structure (Figure 7a) and the TMD (Figure 7b)

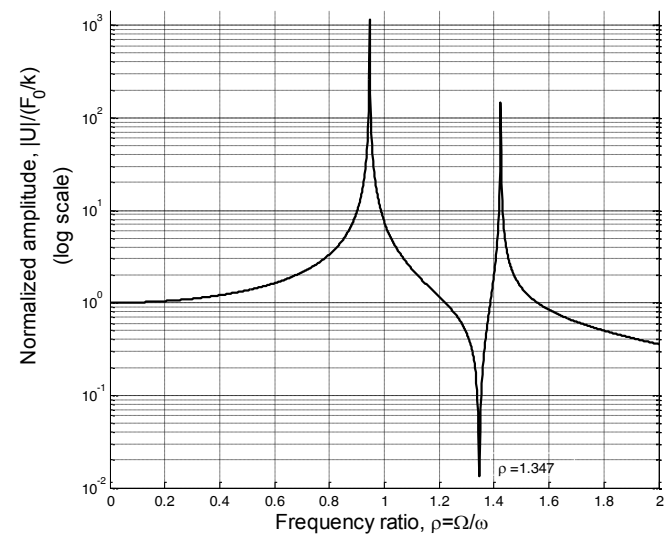

Fig. 7a. Plot showing the steady-state displacement amplitude of the primary structure - the lumped mass of the shear frame

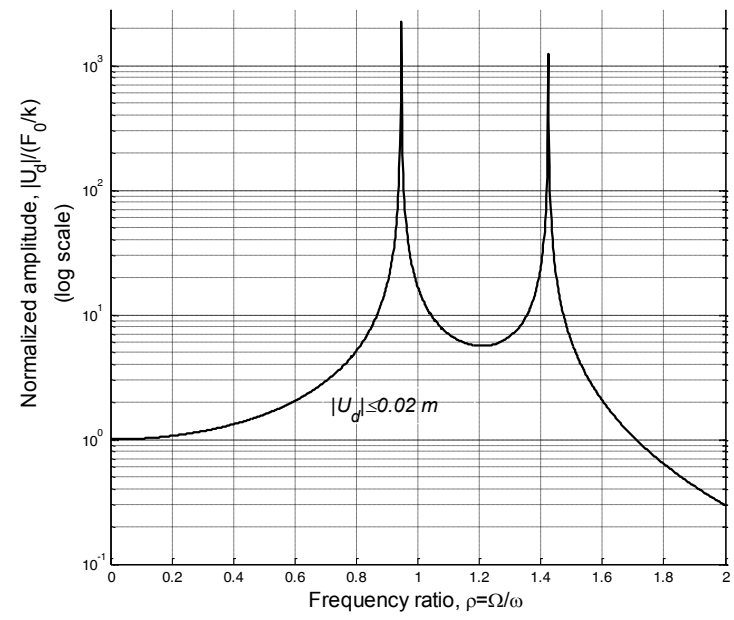

Fig. 7b. Plot showing the steady-state displacement amplitudes of the TMD structure

Second Case - primary structure "control" (undamped shear frame, damped TMD - optimal TMD Design): Design a TMD in such a way that the story displacement of the primary structure remains less than $0.009 \mathrm{~m}^{\prime}$.

Once again, with the help of a Matlab optimization function (absorbmsratio) it is found that the ratio $\mu=m d m$ should be greater than $0.057(m d \sim 5.7 \% \cdot m)$ in order to meet the displacement amplitude constraint of the primary structure - see Figure 8a below 


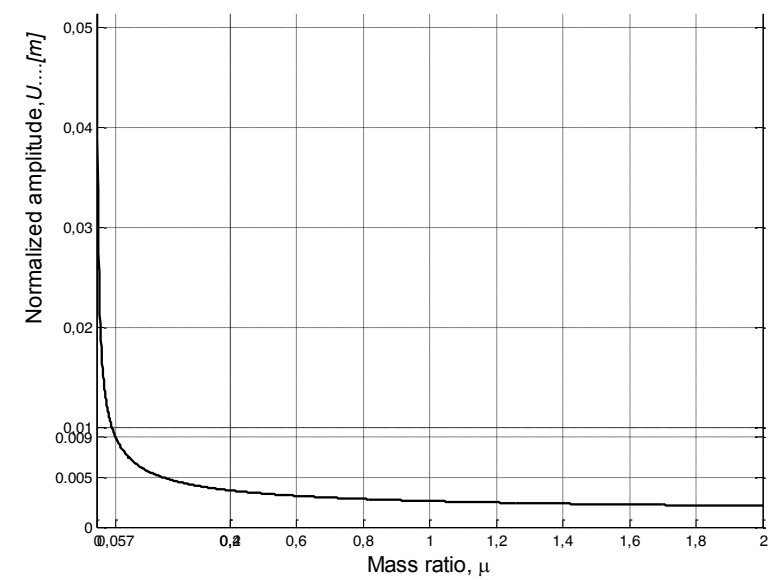

Fig. 8a. Plot showing the steady-state displacement amplitude of the primary structure $v$ s. mass ratio $\mu$, for $\mu=0.057$ on meet the design criteria $u 0<9 \mathrm{~mm}$

Let $\mu=0.06$, then the Matlab script [Bingen Yang] absorbopt yields the optimal TMD parameters as follows:

- the optimal frequency ratio (equation 23) $f$ opt $=0.934$

- optimal damping ratio $\xi d$, opt $=0.14598$

- approximate damping ratio (equation 24) $\xi d$, appr $=0.14569$

- $\quad$ TMD mass $18 \mathrm{~kg}=0.06 * 300$

- TMD damping coefficient $c d=404.804 \mathrm{Ns} / \mathrm{m}$

- $\quad$ TMD stiffness $k d=106799.57 \mathrm{~N} / \mathrm{m}$

- TMD natural circular frequency $\omega d=77.028 \mathrm{rad} / \mathrm{s}$

- Maximum normalized displacement amplitude of the primary structure $U$ p $0 k=5.8649$ at $\rho=0.88784$

- Fixed points $P$ and $Q$ at $\rho 1=0.88453$ and $\rho 2=1.05609$

- Normalized displ. amplitude of the primary structure $U$ p $0 k=5.8595$ in $P$

The two figures, Figure 9a and Figure $9 \mathrm{~b}$ below, show the normalized displacement amplitudes at the optimal damping ratio $\xi d$, opt $=0.14598$ and two other comparing damping ratios.

The maximum displacement amplitude of the primary structure under the so designed and built TMD is $U \max =5.8595 \cdot 3002 \cdot 106=0.00087 \mathrm{~m}<0.009 \mathrm{~m}$

Requirement (design criteria) fulfilled - the shear-frame possess the required stiffness

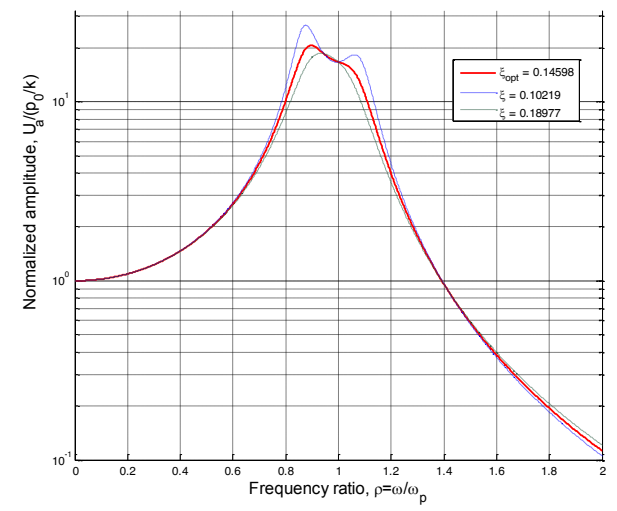

a) 


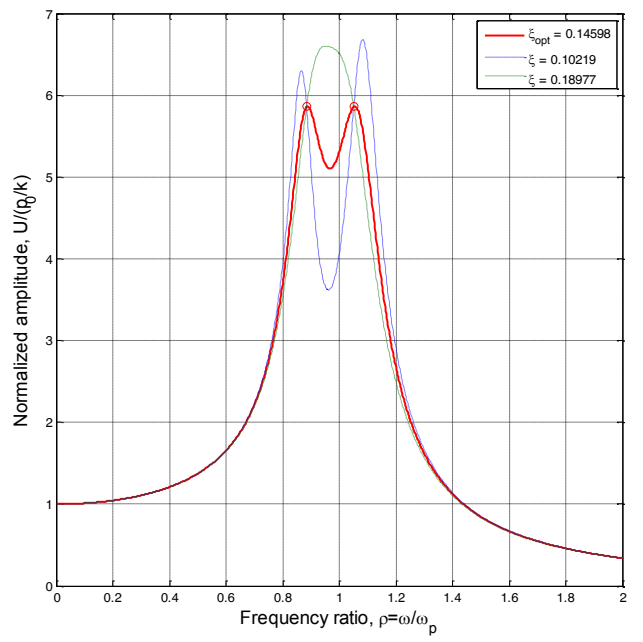

b)

Fig. 9a, b. Plot showing the steady-state displacement amplitudes of the optimally tuned TMD and the primary structure $v s$. frequency ratio $\rho$

\section{Conclusions}

- The TMD can be tuned to a single structural frequency

- The TMD is independent from an external power supply

- Use of inertia force to counteract primary structural motions

- A simple, yet a very elegant way of reducing the structural motions

- The TMD is much more effective for wind induced vibrations than earthquake ones

- The TMD can become out-of-tune or off-tune due to changes in the primary structure' natural frequency, resulting from addition or removal of masses

- Can be used in combination with other structural protective systems

\section{References}

1. Den Hartog J. P. (1947). Mechanical Vibrations, New York: Dover Publications, INC.

2. Ray W. Clough, Joseph Penzien. (1993). Dynamics of Structures: MCGRAW-HILL Second Edition.

3. Bachmann H. (1981). Experiments and Models for the Damping Behaviour of Vibrating Reinforced Concrete Beams in the Untracked and Cracked Conditions: Zürich. ETH.

4. Anil K. Chopra. (2007). Dynamics of Structures: Prentice Hall. Third edition.

5. Der Ingenieurbau. (1999). Technische Mechanik "Grundwissen": Ernst\&Sohn.

6. Soong T. T., G. F. Dargush. (1997). Passive Energy Dissipation Systems in Structural Engineering: Chichester, John Wiley \& Sons Ltd.

7. Soong T. T. (1994). Passive and active structural control: Springer Verlag.

8. Thompson D'Arcy. (1961). On Growth and Form: Cambridge University Press.

9. Feti S., Musa S. (2005). Izolimi sizmik - një shans për të mbijetuar strukturat edhe pas tërmeteve të forta: Tetovë, Simpoziumi SHAIN.

10. François Frey. (2000). Analyse des structures et milieux continus, Lausanne. Traité de Génie Civil de l'EPFL - Mécanique des structures.

11. Chu S. Y., Soong T. T., Reinhorn A. M. (2005). Active, Hybrid and Semi-Active Structural Control, Edition Wiley.

12. www.digitexx.com, www.csiamerica.com 